\title{
Evaluación de la prueba ELISA usando una cepa de campo como antígeno, para detectar anticuerpos contra el virus de la Rinotraqueitis Bovina Infecciosa
}

\author{
Jeannette Navarrete ${ }^{1}$, Víctor Vera ${ }^{2}$, Gloria Ramírez ${ }^{2}$, Luis Carlos Villamil ${ }^{2}$ \\ Universidad Colegio Mayor de Cundinamarca, ${ }^{2}$ Facultad de Medicina Veterinaria y Zootecnia, Programa de Postgrado. \\ Universidad Nacional de Colombia \\ Recibido: 13-07-2004; Aceptado: 22-09-2004
}

\section{Resumen}

El siguiente estudio estableció un inmunoensayo enzimático ELISA, usando partículas virales fraccionadas de una cepa de campo del virus IBR, este mostró una alta sensibilidad y especificidad y una baja tasa de falsos negativos y positivos. Los sueros bovinos positivos y negativos, con los cuales se normalizó la técnica de ELISA, fueron analizados por seroneutralización para determinar anticuerpos anti IBR; se recolectaron sueros negativos y positivos con títulos 1:4 a 1:128 y se consideró la dilución del suero bovino 1:50, como la dilución óptima para la técnica de ELISA. Por otra parte, se utilizó el coeficiente de variación BR, para analizar el grado de repetitibilidad de las absorbancias obtenidas de los sueros positivos y negativos, se obtuvo resultados menores del $20 \%$, lo que indico una adecuada repetitibilidad y un bajo coeficiente de variación. La sensibilidad y especificidad encontrada fue de 96 y $98 \%$ respectivamente, teniendo como prueba de referencia la seroneutralización. Los resultados obtenidos, determinan que la prueba de ELISA con partículas virales fraccionadas de una cepa de campo, detecta anticuerpos anti IBR con alta sensibilidad y especificidad, siendo una herramienta para el mejoramiento diagnóstico de la enfermedad.

Palabras Claves: ELISA, seroneutralización, rinotraqueitis bovina infecciosa, anticuerpos, mejoramiento diagnóstico.

\section{Abstract \\ Evaluation of ELISA test use of field strain (antigen) to detect antibodies against Infectious Bovine Rhinotracheitis virus.}

The following study set up an enzymatic immune test (ELISA) using viral particles broke up of field strain of IBR virus; it showed a high sensibility and specificity and low rate of false negatives and positives. Positive and negative bovine serum which ELISA technique was normalized, were analyzed by seroneutralization to determine anti IBR antibodies; It was collected positive and negative serum with titles 1:4 to 1:128 and was considered dilution of bovine serum 1:50 as optimal dilution to ELISA technique. On the other hand, coefficient of variation BR was used to analyze the rehearsing of absorbance obtained by positive and negative serum. The results obtained were less than $20 \%$, which indicated an appropriate 
trustiness and a low coefficient of variation. Sensibility and specificity found was $96 \%$ and $98 \%$ respectively, taking as a reference test the seroneutralization. The results obtained determined that ELISA test with viral particles broke up of field strain detected anti IBR antibodies with a high sensibility and specificity, being an improvement tool to diagnose the illness.

Key Words: ELISA, seroneutralization, infectious bovine rhinotracheitis, antibodies, diagnostic enhancement.

\section{Introducción}

Los herpes virus bovino tipo 1 (HVB-1), pertenecen a la subfamilia de los Alphaherpesviridae; éstos causan una gran variedad de síndromes que incluyen la rinotraqueitis bovina infecciosa, la vulvovaginitis pustular infecciosa, el aborto, y la conjuntivitis $(1,2)$. La encefalitis bovina se consideraba causada por un agente idéntico al que causa la rinotraqueitis bovina infecciosa, pero por su presentación sintomática exclusiva de signos neurológicos, se sospechó de una variante de este mismo virus. En la actualidad se sabe que la encefalitis bovina es causada por el Herpes Bovino tipo 5 ; estos virus tienen la capacidad de establecer una infección latente en los ganglios nerviosos como el trigémino (3). La transmisión del virus HVB-1 de animal a animal, ocurre comúnmente por introducción de animales infectados en hatos sanos (2). El diagnóstico confirmatorio puede realizarse por el aislamiento del virus en células renales bovinas, y la posterior identificación se da por sus efectos citopáticos específicos $(4,5)$.

Con pruebas serológicas, como la neutralización viral se puede analizar la respuesta humoral desde la óptica del control sobre la infectividad del virus en un cultivo celular, lográndose detectar la presencia de anticuerpos en muestras dobles, tomadas en la fase aguda y de convalecencia; llegando así a un diagnóstico certero por la seroconversión (incremento en el título de anticuerpos al cuádruple), siendo una prueba positiva para la presencia del virus de $\operatorname{IBR}(6,7)$.

Igualmente, la presencia de anticuerpos anti-IBR, puede ser detectada por ELISA en muestras de leche, donde se han detectado seroconversiones en un $70 \%$ de la población estudiada (8).
Así mismo, se ha demostrado una elevada sensibilidad $(100 \%)$ y especificidad $(91 \%)$ de la prueba ELISA para detectar seroconversión, en muestras pareadas de animales infectados por el virus IBR (9); este procedimiento se ha usado para la detección de anticuerpos específicos contra glicoproteínas del virus HVB-1 $(10,11)$.

Este estudio presenta un inmunoensayo enzimático (ELISA) altamente sensible y específico, utilizando partículas virales de una cepa de campo, con la cual se hace reaccionar sueros bovinos y anticuerpos monoclonales dirigidos contra proteínas del virus IBR.

\section{Materiales y métodos}

Sueros bovinos: los sueros bovinos positivos y negativos (seroneutralización) se obtuvieron del banco de sueros del programa de postgrado de la Facultad de Medicina Veterinaria y de Zootecnia de la Universidad Nacional de Colombia. Los títulos de anticuerpos anti IBR por seroneutralización fueron de 1:4 hasta 1:128; igualmente, se procesó en este estudio un suero hiperinmune obtenido en conejo con anticuerpos policlonales contra el virus.

Células: las células se obtuvieron realizando cultivos (frascos Roux) de la línea celular de riñón bovino o Madin-Darby (MDBK) (ATCC CCL 22); se mantuvieron en crecimiento por 24 horas a $37^{\circ} \mathrm{C}$, en Medio Esencial Mínimo (MEM) (SIGMA), suplementado con suero bovino fetal al 7\% (Laboratorios Hyclone), L glutamina 1\% (SIGMA) y antibióticos al 1\% (solución de penicilina 10.000U, Streptomicina $10 \mathrm{mg}$, Anfotericina $25 \mathrm{mg}$ Hibrimax SIGMA). Las 
células se incubaron con el medio hasta obtener confluencia celular del 70 a $90 \%$ (12).

Cepas virales: Se utilizó una cepa de campo, aislada de un toro en servicio, proveniente de un hato de la Sabana de Bogotá, sin antecedentes de vacunación a IBR $y$ con seroconversión por prueba de seroneutralización. La cepa fue cultivada en células MDBK, de acuerdo con el siguiente protocolo: el virus fue absorbido durante 1 hora a $37^{\circ} \mathrm{C}$ en las células MDBK, se adicionó $70 \mathrm{ml}$ de MEM al 1\%, se incubó 24 horas a $37^{\circ} \mathrm{C}$ (efecto citopático del $80-100 \%$ de las células), el sobrenadante se clarificó centrifugándolo a $15000 \mathrm{~g}$ (Centrífuga Beckman J21) por $20 \mathrm{~min}$ a $4^{\circ} \mathrm{C} \mathrm{y}$ se conservó a $-80^{\circ} \mathrm{C}$.

Cuantificación de proteinas: para la cuantificación de proteínas se utilizó la prueba espectofotométrica de Bradford; ésta permitió una sensibilidad de detección de proteínas en la muestra a analizar de 60-300 mg/ml (13). Considerando que los lotes de virus de la cepa de campo fueron cosechados en medio MEM con SBF, el diluyente para la prueba Bradford se preparó con el mismo medio, con el fin de cuantificar de forma real la concentración de proteínas virales. La determinación de proteínas de las cepas del virus del IBR, presentó un porcentaje de confiabilidad de $99.7 \%$ (13).

Seroneutralización: los sueros bovinos que contenían los anticuerpos contra las partículas del virus IBR se usaron como controles positivos, se inactivaron en baño maría a $56^{\circ} \mathrm{C}$ por $30 \mathrm{~min}$. Se realizaron diluciones en base 2 de cada uno de los sueros hasta la dilución 1:128; posteriormente se adicionaron 50 ul de la suspensión del virus (dilución de trabajo) que contenía 100 DITC 50\% del virus cepa de referencia Iowa y se incubaron a $37^{\circ} \mathrm{C} \mathrm{du}$ rante 1 hora. Luego se colocaron $50 \mathrm{ul}$ de la suspensión de células (suspensión de células MDBK, ajustada a una concentración de 25.000 células/50ul en medio de cultivo suplementado con suero bovino fetal al 5\%, glutamina $2 \%$ y antibiótico $1 \%$ ). Las placas se incubaron a $37^{\circ} \mathrm{C}$ por 72 horas. Se determinó el título seroneutralizante para cada uno de los sueros problema, previa verificación del resultado de los controles empleados en la prueba, considerándose como positivo un título 1:4 (14).

Inmunodot: una de las variantes del ELISA es el dot-ELISA, también conocida como inmunopunto o dotblot, el cual emplea una membrana de nitrocelulosa como soporte para el acoplamiento del antígeno en lugar del soporte de poliestireno empleado en el ELISA convencional (15). El inmunodot se utilizó para encontrar la concentración óptima del antígeno, anticuerpo primario y conjugado (proteina G marcada con peroxidasa), necesarios para la realización del ensayo. Se recortó papel de nitrocelulosa del tamaño de una caja de 96 pozos para realizar el marcaje en donde se depositó el antígeno. El papel se lavó con buffer TBS (Buffer Tri salino) y se dejó secar. El virus ( $5^{\circ}$ Pase) fue sonicado a $40 \mathrm{MHz}$ (Ultrasonic Homogenizer Cole Parmer Instruments 4710 ) por $60 \mathrm{~s} \mathrm{a} 4^{\circ} \mathrm{C}$, con intervalos de 30 s por dos veces; se adicionaron $4 \mu \mathrm{ldel}$ mismo por pozo demarcado, se dejó secar por 5 a 10min a temperatura ambiente. Posteriormente se bloqueó con TBS-Tween $200.05 \%$ leche descremada $5 \%$ por 24 horas a $4^{\circ} \mathrm{C}$. Se lavó nuevamente y se adicionaron, utilizando una caja de 96 pozos, $100 \mu 1$ del anticuerpo primario, y se colocó en contacto con el papel, se incubó a $4^{\circ} \mathrm{C}$ una noche en cámara húmeda; nuevamente se lavó tres veces con buffer TBS 5 min en agitación a temperatura ambiente, a continuación se adicionó $100 \mu 1$ del conjugado (la proteína $\mathrm{G}$ marcada con peroxidasa Pierce) a título de trabajo y se incubó toda la noche a $4^{\circ} \mathrm{C}$ en cámara húmeda. Finalmente se lavó el papel para adicionar el sistema de revelado $(19 \mathrm{ml}$ de Buffer acetato, $60 \mu \mathrm{l}$ de $\mathrm{H}_{2} \mathrm{O}_{2}$ y $1 \mathrm{ml}$ de solución de aminoetilcarbazol en dimetil formamida), después de 10 a 30min la reacción se detuvo con 2 lavados en agua destilada $(16,17)$.

Inmunoensayo enzimático (ELISA): considerando que el inmunoensayo enzimático, ELISA, facilita

www.unicolmayor.edu.co 
la detección de anticuerpos IgG contra el virus de la rinotraqueitis bovina infecciosa, se siguió y modificó el protocolo sugerido por Vandrunen (1984). En placas de poliestireno Inmulon II, se adicionaron $100 \mu 1$ del virus diluido ( $2 \mathrm{ml}$ de la cepa de campo a una concentración de proteínas de $6.38 \mathrm{mg} / \mathrm{ml}$, se sonicó, y el antígeno se diluyó 1:4 buffer cubierta de $\mathrm{Na}_{2} \mathrm{CO}_{3} /$ $\mathrm{NaHCO}_{3} 0.2 \mathrm{M} \mathrm{pH} \mathrm{9,6),} \mathrm{las} \mathrm{placas} \mathrm{se} \mathrm{incubaron} 1$ hora a $37^{\circ} \mathrm{C}$ y 24 horas a $4^{\circ} \mathrm{C}$ en cámara húmeda. Se procedió a lavar dos veces con PBS-Tween- leche (buffer fosfato $0.15 \mathrm{M} \mathrm{pH} 7,2,0.05 \%$ de Tween 20, $5 \%$ de leche descremada) y se bloqueó con $100 \mu 1$ de esta misma solución, por 24 horas a $4^{\circ} \mathrm{C}$ en cámara húmeda. Se agregó $100 \mu 1$ a cada pozo de las diluciones del suero de los ratones 1:25 en PBS Tween-leche y el sobrenadante concentrado de los híbridomas y se incubaron 1 hora a $37^{\circ} \mathrm{C}$ en cámara húmeda, posteriormente, se lavaron 5 veces con PBS Tween y las placas se secaron bien en el último lavado. Se adicionó $100 \mu 1$ de la proteína $\mathrm{G}$ marcada con peroxidasa (Pierce) a título de trabajo (1:6000) y se incubó 1 hora a $37^{\circ} \mathrm{C}$ en cámara húmeda; nuevamente se lavaron las placas 4 veces con PBS Tween y una vez con PBS y se secaron bien en el último lavado se adicionó $100 \mu 1$ de buffer revelado (Buffer citrato fosfato $\mathrm{pH} 5,0$, ortophenilendiamina y $\mathrm{H}_{2} \mathrm{O}_{2}$ ) y a los 10 min se frenó la reacción con $\mathrm{H}_{2} \mathrm{SO}_{4} 2 \mathrm{~N}$; las absorbancias se leyeron en un espectrofotómetro (Dynatech Lab.) a 492nm. Como controles positivos y negativos determinados por seroneutralización, se usaron sueros bovinos y un suero hiperinmune contra IBR obtenido de conejo.

\section{Resultados}

La cuantificación de proteínas se realizó por el método Bradford (4), como método confirmatorio y a la vez cuantitativo de la presencia de proteínas virales. La concentración de proteínas fue de 0.638 $\mathrm{mg} / \mathrm{ml}$ para la cepa de campo y de $1.399 \mathrm{mg} / \mathrm{ml}$ para la cepa de referencia Iowa (Tabla 1).
Tabla 1. Titulación y cuantificación de proteínas de la cepa de campo y de referencia lowa del virus IBR.

\begin{tabular}{|c|c|c|}
\hline Copa virus & Titulo & $\begin{array}{c}\text { Proteinas } \\
(\mathbf{m g} / \mathrm{m})\end{array}$ \\
\hline IOWA & $1 \times 10^{-5.25}$ & 1.399 \\
\hline Cepa de campo 1999 & $1 \times 10^{-5.13}$ & 0.638 \\
\hline
\end{tabular}

Para realizar un análisis óptimo del ELISA, los inmunoreactantes se titularon utilizando la técnica de inmunodot. La concentración óptima de las partículas virales fraccionadas fue en la dilución 1:4; la concentración óptima para el anticuerpo primario obtenido de sueros bovinos usados como controles positivos y negativos se determinó en la dilución 1:25, para el suero hiperinmune contra el virus IBR obtenido en conejo 1:50 y para la proteína G 1:6000.

Para establecer la dilución óptima del suero que reconociera las partículas virales sin que las absorbancias de las muestras positivas estuvieran muy cercanas a las negativas, se utilizó el coeficiente BR, el cual se calcula con las absorbancias de las diluciones de sueros positivos sobre las absorbancias de las diluciones de los sueros negativos. La dilución del suero bovino donde se encontró mayor distancia entre el resultado positivo y el negativo fue la dilución 1:50 y la dil 1:200. Se consideran estas diluciones del suero adecuadas para obviar reacciones inespecíficas (Figura 2)
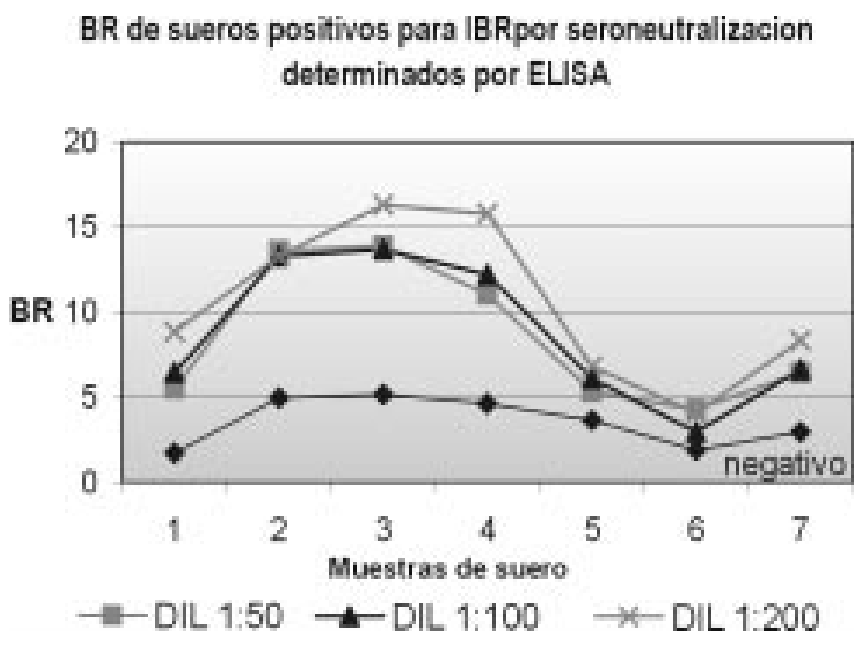

Figura 2. Coeficiente BR de sueros bovinos positivos/negativos en diluciones 1:50, 1:100 y 1:200 
Para seguir con la normalización de un ensayo es necesario que este ofrezca indicios preliminares de repetitibilidad. Para este análisis, se tomaron sueros positivos por seroneutralización (títulos de 1:16, 1:64 y $1: 128)$ procesados dentro de una misma serie, repitiendo 20 veces el mismo suero en dilución 1:50. Los resultados en cada suero demostraron un coeficiente de variación de 15 a $19 \%$.

La sensibilidad y especificidad de la ELISA normalizada con partículas virales de la cepa de campo, se determinaron con 50 sueros bovinos positivos y 50 sueros bovinos negativos por seroneutralización, en dilución de trabajo 1:50 y 1:200, de acuerdo con el coeficiente BR analizado anteriormente. El análisis de sensibilidad y especificidad se realizó utilizando el programa Win Episcope 2.0.

Para los sueros procesados en dilución 1:50, la sensibilidad y especificidad fue de $96 \%$ y $98 \%$, teniendo como prueba de oro la seroneutralización; estos resultados tuvieron un nivel de confianza del $95 \%$. El valor predictivo positivo y valor predictivo negativo fue de $97.9 \%$ y $96 \%$. La sensibilidad y especificidad de los mismos sueros procesados en dilución 1:200 fue de $70 \%$ y $100 \%$ con valor predictivo positivo y negativo de 100 y $76.9 \%$ respectivamente.

Como un procedimiento adicional para verificar el coeficiente del ELISA, se empleó un evaluador del valor predictivo que busca establecer las concordancias de las pruebas (seroneutralización y ELISA) denominado evaluación cualitativa de kappa ó coeficiente de concordancia de medidas. Si este coeficiente kappa es bajo, existe incertidumbre en los datos reportados. Bajo estas circunstancias, una prueba diagnóstica alternativa tiene que ser comparada con un test estándar. La concordancia o conformidad entre ambas pruebas se expresa por el valor kappa (18). En los resultados del presente trabajo, usando los sueros en dilución 1:50, el valor kappa fue de 0.94 con un nivel de confianza del 95\%.

Correspondencia: revistanova@unicolmayor.edu.co

\section{Discusión}

Se considera una prueba serológica validada, cuando arroja resultados que revelan la presencia o ausencia de anticuerpos o antígenos en suero con un margen determinado de confianza estadística (7). Este estudio buscó normalizar una prueba de ELISA sencilla, económica de alta sensibilidad y especificidad, la cual servirá como herramienta diagnóstica útil para en los programas de control del virus IBR. Una adecuada concentración de proteínas utilizadas como antígeno en este caso, contribuye como factor importante en la normalización de un inmunoensayo enzimático (19).

A partir de los resultados del inmunodot, se pudieron establecer las condiciones óptimas para cada uno de los inmunoreactantes utilizados en ELISA, en donde la dilución que se usó del antígeno viral fue 1:4 y de la peroxidasa 1:6000.

En los kits comerciales se establece un procedimiento confirmatorio de la presencia de anticuerpos anti IBR en muestras sospechosas, realizando el ELISA por duplicado, en pozos que contengan partículas virales y en pozos que no contengan el virus.

Para ser más exigentes en la normalización de la ELISA del presente estudio, todos los sueros procesados se montaron por duplicado, en pozo con partículas virales y su duplicado (pozo con sobrenadante de células MDBK en cultivo). Al realizar este procedimiento se observó una reacción inespecífica de todos los sueros tanto positivos como negativos en el pozo que no contiene partículas virales, esto posiblemente se debe a la presencia de anticuerpos contra proteínas de las células bovinas. Se determinó la diferencia entre las absorbancias totales (virus y células) menos las absorbancias de los sobrenadantes celulares para obtener una absorbancia neta.

Al encontrarse un coeficiente de variación del 15 al $19 \%$ se puede decir que existe un nivel adecuado de repetibilidad, ya que un coeficiente de variación es menor del $20 \%$ en las absorbancias analizadas (7). 
Lo anterior indica que los resultados de absorbancias netas del ELISA normalizado, demuestran un grado muy bajo de variación entre resultados de la misma muestra (20).

En la ELISA normalizada se encontró una la sensibilidad y especificidad del $96 \%$ y $98 \%$ respectivamente, con un valor predictivo positivo del $97.9 \% \mathrm{y}$ valor predictivo negativo $96 \%$, lo que indica que la prueba de ELISA que se normalizó con partículas virales de la cepa de campo ofrece garantías adecuadas para un acertado diagnóstico serológico de la presencia de anticuerpos anti IBR.

Los resultados de la dilución 1:200 en los sueros bovinos, no evidencia una sensibilidad adecuada para una prueba diagnóstica, por lo tanto se decidió procesar los sueros en la dilución 1:50 donde se evidencia mayor sensibilidad para detectar anticuerpos anti IBR.

En muchas circunstancias, es difícil y costoso diferenciar el estado real del estado de la enfermedad. Por lo tanto, en la práctica los clínicos tienen que utilizar con frecuencia reacciones en las que no hay estimación cuantitativa de sensibilidad y especificidad; admitiendo tácitamente que el valor predictivo puede ser suficientemente aceptable con fines prácticos (18).

El valor kappa de 0.94 , valor cercano a 1, indica que existe un nivel de concordancia de medidas muy cercano a la realidad de lo que se esta midiendo, tomando como referencia la ELISA normalizada y la seroneutralización como prueba de oro (19).

Por lo anterior, el ELISA descrito en el presente trabajo es altamente sensible y específico para la detección de anticuerpos IgG contra el virus IBR y se recomienda como herramienta diagnóstica para detectar la presencia de la enfermedad en sueros de Bovinos. Sería de gran utilidad, ver el comportamiento de esta prueba para evaluar datos epidemiológicos en áreas endémicas de baja o alta prevalencia, o en áreas donde no se conoce el estado de la enfermedad causada por el virus de IBR.
Mediante el desarrollo de una herramienta diagnóstica óptima para la detección directa o indirecta de los agentes causales de las enfermedades virales, en este caso de la rinotraqueitis bovina infecciosa, el presente trabajo contribuye con el estudio de patologías que afectan a los bovinos en Colombia.

\section{Refencias}

1. Babiuk LA, Wardley RC, Rouse BT. Defense mechanisms against bovine herpesvirus: relationship of virus host cells events to susceptibility to antibody complement lysis. Infect Immun 1975; 12:958-63.

2. Bradford M. A rapid and sensitive method for the quantitation of microgram quantities of protein. Anal Biochem 1976; 72: 248.

3. Ciacci-Zanella J, Stone M, Henderson G, Jones CM. The latencyrelated gene of bovine herpes virus 1 inhibits programmed cell death. J Virol 1999; 73(12):9734-40.

4. Deutscher MP. Guide to protein purification. EUA. Academic Press INC: 1990; 182p

5. Fenner F, y otros. Virología Veterinaria. Editorial Acribia S.A.;1992.

6. Graham DA, McShane J, Mawhinney KA, McLaren IE, Adair BM, Merza M. Evaluation of a single dilution ELISA system for detection of seroconversion to bovine viral diarrhea virus, bovine respiratory syncytial virus, parainfluenza virus and Infectious Bovine Rhinotracheitis virus: comparison with testing by virus neutralization and hemagglutination inhibition. J Vet Diag Inves 1998; 10(1): 43-8

7. Jacobson RH. Validación de pruebas serológicas para el diagnóstico de enfermedades infecciosas. Rev Sci Tech Off Int Epiz $1998 ; 17(2): 507-26$.

8. Kairs R.F. Infectious bovine rhinotracheitis: A review and update. J Am Vet Med Assoc 1977; 71:1055-64.

9. Kramps JA, Magdalena J, Quak J, Weerdmeester K, Kaashoek Maris-veldhuis MA, Rijsewijk Fam, et al. A simple, specific and highly sensitive blocking enzyme-linked immunosorbent assay for detection of antibodies to bovien herpesvirus 1. J Clin Microbiol 1994; 32(9):2175-2181.

10. Lemaire M, Meyer G, Baranowski E, Schynts F, Wellemans G, Kerkhofs $\mathrm{P}$, et al. Production of bovine herpesvirus type 1 seronegative latent carriers by administration of a liveattenuated vaccine in passively immunized calves. J Clin Microbiol 2000; 38(11):4233-8.

11. Misra V, Blumenthal M, Babiuk LA. Proteins specified by bovine Herpesvirus 1 (Infectious Bovine Rhinotracheitis Virus). J Virol $1981 ; 40(2): 367-378$

12. Mohanty SB, Dolla SK. Virología Veterinaria. 1aㅗ ed. México: Editorial Interamericana; 1983.

13. Molano D, Rodríguez JL, Ramírez G, Villamil LC. Caracterización electroforética e inmunológica de una cepa de campo del virus de la rinotraqueitis infecciosa bovina y su comparación con cepas de referencia. Rev Med Vet Zootec 1996; 44:35-8.

14. Pritchard GC, Krikwood GM, Sayers AR. Detecting antibodies to Infectious Bovine Rhinotracheitis and BVD virus infection using milk samples from individual cows. Vet Rec 2002; $150(6): 182-3$.

15. Pritchard GC, Banks M, Vernon RF. Subclinical breakdown with Infectious Bovine Rhinotracheitis virus infection in dairy herd of high health status. Vet Rec 2003; 153(4):113-7.

16. Sambrook J, Fritsch EF, Maniatis T. Molecular cloning a Laboratory Manual. 2 ${ }^{\underline{a}}$ ed. U.S.A: Cold Spring Harbor Laboratory Press; 1989. 
17. Solis Calderon JJ, Segura Correa VM, Segura Correa JC, Alvarado Islas A. Seroprevalence and risk factors of Infectious Bovine Rhinotracheitis in beef cattle herds of Yucatan, Mexico. Prev Vet Med 2003; 57(4):199-208.

18. VanDrunen Littel Van den hurk S, Van den hurk JV, Gilchrist JE, Misra V, Babiuk LA. Interactions of monoclonal antibodies and bovine Herpesvirus type 1 (BHV-1) glycoproteins: characterization of their biochemical and immunological properties. Virol 1984; 135:466-79
19. VanDrunen littel Van den hurk S, Babiuk LA. Synthesis and processing of Bovine Herpesvirus 1 glycoproteins. J Virol 1986; 59(2):401-10.

20. Wellenberg GJ, Verstraten E, Mars MH, Van Oirschot JT. ELISA detection of antibodies to glycoprotein $\mathrm{E}$ of bovine herpesvirus 1 in bulk milk samples. Vet Record 1998; 28:219-20.

www.unicolmayor.edu.co 